\title{
Effects of in-stream structures and channel flow rate variation on
}

\section{transient storage}

\author{
SM Masud Rana ${ }^{1}$, Durelle T. Scott ${ }^{2}$, Erich T. Hester ${ }^{1}$ \\ ${ }^{1}$ Department of Civil and Environmental Engineering, Virginia Tech, Blacksburg, Virginia, \\ USA. \\ ${ }^{2}$ Department of Biological Systems Engineering, Virginia Tech, Blacksburg, Virginia, USA.
}

\begin{abstract}
In-stream structures can potentially enhance surface and subsurface solute retention. They form naturally in small streams and their installation has gained popularity in stream restoration for multiple purposes, including improved water quality. Yet few studies have quantified the cumulative effect of multiple structures on solute transport at the reach scale, nor how this varies with changing stream flow. We built a series of weirs in a small stream to simulate channel spanning structures such as natural debris dams and stream restoration log dams and boulder weirs. We conducted constant rate conservative $(\mathrm{NaCl})$ tracer injections to quantify the effect of the weirs on solute transport at the reach scale. We used a one dimensional solute transport model with transient storage to quantify the change of solute transport parameters with increasing number of weirs. Results indicate that adding weirs significantly increased the crosssectional area of the surface stream $(A)$ and transient storage zones $\left(A_{S}\right)$ while exchange with transient storage ( $\alpha$ ) decreased. The increase in $A$ and $A_{s}$ is due to backwater behind weirs and
\end{abstract}


increased hydrostatically driven hyporheic exchange induced by the weirs, while we surmise that the reduction in $\alpha$ is due at least in part to reduced hydrodynamically driven hyporheic exchange in bed ripples drowned by the weir backwater. In order for weir installation to achieve net improvement in solute retention and thus water quality, cumulative reactions in weir backwater and enhanced hydrostatically driven hyporheic exchange would have to overcome the reduced hydrodynamically driven exchange. Analysis of channel flow variation over the course of the experiments indicated that weirs change the relationship between transient storage parameters and flow, for example the trend of increasing $\alpha$ with flow without weirs was reversed in the presence of weirs. Effects of flow variation were substantial, indicating that transient storage measurements at a single point in time typically cannot be extrapolated to estimate net annual effects. Thus, rigorous evaluation of water quality effects of stream restoration structures requires measurements at multiple channel flow rates. 


\section{Introduction}

Human development such as agriculture and urbanization strongly affects streams (Wenger et al., 2009), including loss of ecosystem function (FISRWG, 1998; USEPA, 2006) due to excess nitrogen and phosphorus, riparian disturbance, higher peak flow, and mobilized sediments (Howarth et al., 2002). Excess nutrient delivery in turn causes eutrophication in downstream waters such as the Chesapeake Bay, Gulf of Mexico, and Long Island Sound (Breitburg et al., 1999; Houde et al., 1999; Kemp et al., 2005; Scavia and Bricker; USEPA, 2010). Streams receive, assimilate, and transport nutrients (Bernhardt et al., 2003, 2005), and can be a hotspot for excess nutrient removal (Seitzinger et al., 2002).

The practice of stream restoration can improve habitat in degraded streams and benefit water quality by removing dissolved nutrients such as nitrogen (Baron et al., 2002; van Driel et al., 2006; Bukaveckas, 2007; Craig et al., 2008; Lawrence et al., 2013; Mueller et al., 2014; Scott et al., 2014; Veraart et al., 2014; Johnson et al., 2015). Stream restoration often entails stream channel modifications that reduce surface velocities and promote exchange with the subsurface (hyporheic exchange). Common structures used for this purpose include cross-vanes, J-hooks, channel spanning logs, boulder weirs, and root wads (Doll et al., 1999; Roni et al., 2006; Daniluk et al., 2013; Miller and Kochel, 2013; Palmer et al., 2014). These structures can also potentially improve water quality by regulating temperature (Arrigoni et al., 2008; Hester et al., 2009; Menichino and Hester, 2014), removing toxins (Bencala and Walters, 1983; Harvey and Fuller, 1998; Fuller and Harvey, 2000), and retaining excess dissolved and suspended nutrients (Craig et al., 2008; Hester et al., 2016). Regulatory bodies, such as the Chesapeake Bay Program (CBP) and the Western Oregon Stream Restoration Program, provide support and guidelines for 
restoring water quality in regional water bodies. For example, the Chesapeake Bay program, which was formed to lead the restoration of water quality in the Chesapeake Bay region encourages structures like debris dams and brush sills for nutrient removal (Berg et al., 2014).

Velocity reducing stream restoration structures can potentially modify transient storage, which has been defined as the temporary retention of flow and solute from the main channel (Bencala and Walters, 1983) that ultimately returns to the main channel. Transient storage can occur on the surface (exchange with off-channel dead zones - surface transient storage) and in the shallow subsurface (hyporheic transient storage). The latter, generally having more reactive surface area and longer residence time, is considered more conducive to chemical or biogeochemical reactions beneficial to water quality (Hester and Gooseff, 2010; Hester et al., 2013). The transient storage model describes solute transport in a stream using the one dimensional advection dispersion equation augmented with terms representing exchange with immobile transient storage zones along the reach (Bencala and Walters, 1983). The size of the overall transient storage zone and exchange rate between main channel and transient storage zone can be estimated by fitting measured tracer breakthrough data, and provide a convenient way of measuring the "potential" of the stream to retain and process solutes (Bencala et al., 1990; Workshop, 1990; D’Angelo et al., 1993; Hall et al., 2002; Ensign and Doyle, 2005; Lautz and Siegel, 2007; Gordon et al., 2013; Zarnetske et al., 2015).

Studies have shown that in-stream structures drive hyporheic exchange (Lautz and Siegel, 2006; Hester and Doyle, 2008; Daniluk et al., 2013), yet fewer studies have evaluated transport of nutrients that impair water quality. Studies of individual structures such as log dams have shown that they increase biogeochemical or thermal heterogeneity in the subsurface thereby 
creating biogeochemical hotspots (Kasahara and Hill, 2006; Lautz and Fanelli, 2008; Menichino and Hester, 2014), but fewer studies have evaluated cumulative reach scale effects. Briggs et al. (2013) found that hyporheic zones induced by beaver dams can create localized hotspots for nutrient processing but their net effect on nutrient removal at the reach scale was minimal. Gordon et al. (2013) studied cross-vanes and similarly concluded insignificant reach scale impact. Hines and Hershey (2011) did not find significant difference in ammonium uptake across completed restoration structures like cross-vanes. In modeling studies, Azinheira et al. (2014) and Hester et al. (2016) found insignificant impact of hyporheic exchange induced by two instream weirs in a $90 \mathrm{~m}$ reach. Zimmer and Lautz (2015) studied the addition of a single cross vane and concluded that if head gradient across the structure is too large, it may induce hyporheic exchange with residence times that are too short to promote significant nutrient processing.

The cumulative effect of a series of structures has shown greater potential than single structures to increase transient storage. Jin et al. (2009) found that transient storage area increased with the number of beaver dams. Ensign and Doyle (2005) observed higher ammonium and phosphate uptake velocity after adding a series of flow baffles in a stream. Roberts et al. (2007) observed that adding a series of flow-obstructing logs enhanced transient storage and ammonia uptake. Transient storage parameter estimation is strongly dependent on channel flow, as shown by multiple studies (Valett et al., 1996; Hall et al., 2002; Ward et al., 2013a, 2013b). Yet, to the best of our knowledge, no studies so far have systematically related the presence or number of instream structures to transient storage parameters (e.g., cross-sectional area, transient storage size) while simultaneously evaluating the effects of varying channel flow rate. Yet, such 
relations are key to understanding the impact of stream restoration structures on solute transport and may allow better prediction of their effects on water quality.

The overall aim of this study was to measure the effect of multiple small channel spanning structures (representing typical restoration structures such as log dams and boulder weirs) on solute transport and transient storage characteristics of a stream. Our main objective was to test the effect of increasing number of in-stream structures on transient storage. Specific

expectations were that: 1) weir construction would increase surface transient storage by creating pools and zones of slow moving water; 2) weir construction would enhance hyporheic transient storage zone size and exchange by creating hydrostatic head gradient across the weirs; and 3) increasing the number of weirs would correspondingly enhance transient storage parameters. A secondary objective was to quantify the hydrologic transport effects of structures across a range of channel flow rates.

\section{Methods}

\subsection{Study Site and Background Hydrologic Monitoring}

The field site is a second order (field observation and USGS topo maps) stream dominated by riffle-pool and step-pool (log dam) features located in the Jefferson National Forest in southwestern Virginia $\left(37^{\circ} 20^{\prime} \mathrm{N} 80^{\circ} 21^{\prime} \mathrm{W}\right)$. The stream drains a catchment of about $1 \mathrm{~km}^{2}$ (Figure 1) and eventually flows to the James River and the Chesapeake Bay. Stream flow at the project reach is highest during the winter and sometimes becomes intermittent during late summer and early autumn. Background specific electrical conductance increases with decreasing 
flow and ranges between 15 and $25 \mathrm{uS} / \mathrm{cm}$. Experiments were conducted during the late spring baseflow recessions between May 11 and June 9, 2015 with flow declining from 14 to $4 \mathrm{~L} / \mathrm{s}$.

Our experiments utilized a control reach (MS1 to MS2) and a treatment reach (MS2 to MS3) downstream of the control reach (Figure 1). The two reaches were both $80 \mathrm{~m}$ in length (measured along the thalweg) and are contiguous with very similar geomorphology and bed material. The primary purpose of the control reach was to help interpret changes in the treatment reach, allowing us to better distinguish effects of experimental manipulation from those due to natural channel flow variability. The control reach has an average slope of $0.056 \mathrm{~m} / \mathrm{m}$ and the treatment reach has an average slope of $0.066 \mathrm{~m} / \mathrm{m}$ (both have a measurement error of $\pm 0.001 \mathrm{~m}$ ). The upper half of the control reach lies adjacent to the end of a steep hill slope, while the remaining portion of the control reach and the entire treatment reach had comparatively flat floodplains on both banks. The channel is typically about $2 \mathrm{~m}$ wide and $0.5 \mathrm{~m}$ deep with near vertical banks. Based on visual observation, winter high flows were generally contained within the channel.

We also installed a stilling well in the stream channel at the upstream end of the treatment reach. We measured absolute pressures in the stilling well (surface water), and in the air with HOBO pressure transducer sensor-loggers (Onset, Bourne, MA). Water depths were calculated by subtracting atmospheric pressure from the absolute pressures and dividing by the specific weight of water. The HOBOs logged pressure continuously in the stream at 15 min intervals starting in July 2014.

\subsection{Stream Tracer Injection and Weir Construction}

We performed six experiments (E1 through E6) that differed in terms of number of in-stream structures and/or flow rate in the channel (Table 1). We installed a series of structures (weirs) in 
the treatment reach to simulate natural debris dams as well as stream restoration structures such as log dams, boulder weirs, w-weirs, and upstream v's (Bilby and Likens, 1980; Brooks et al., 2004; Roni et al., 2006; Bhuiyan et al., 2007; NRCS, 2007; Miller and Kochel, 2013). We varied the number of structures from 0 to 10 and installed them in stages between E1, E2, E3, and E4 to test the effect of weir number/density on transient storage parameters. Each weir entailed a single $5 \times 20 \mathrm{~cm}$ wooden board ranging in length from $2.4 \mathrm{~m}$ to $3.6 \mathrm{~m}$ installed perpendicularly across the channel and buried on average $2.5 \mathrm{~cm}$ to $5 \mathrm{~cm}$ into the channel bottom. For each experiment, we waited from 2-7 days between structure construction and tracer injection for the disturbed sediments to settle. We repeated the 10-weir experiment twice (three events in total) to study the effect of changing channel flow on the estimation of transient storage parameters.

We injected $\mathrm{NaCl}$ as a conservative tracer $40 \mathrm{~m}$ upstream of the upstream end of the control reach ("Injection" in Figure 1) to allow for mixing of tracer before measurement at MS1. We mixed $\mathrm{NaCl}$ with stream water on the day of the injection in quantities which would increase the specific electrical conductance by about $150 \mu \mathrm{S} / \mathrm{cm}$. Injection duration ranged from 3.0 to 4.8 hours depending on stream flow to ensure steady state concentration was achieved. We measured specific conductance (as a surrogate for $\mathrm{Cl}^{-}$) with YSI Pro Plus Multiparameter conductivity probes (YSI Incorporated, Yellow Springs Ohio) at the upstream end of the control reach (MS1), the downstream end of the control reach (MS2), and the downstream end of the treatment reach (MS3) (Figure 1). We also measured background specific conductance with a Solinst LTC (Ontario, Canada) probe $20 \mathrm{~m}$ upstream of the injection location ("Background" in Figure 1). Specific conductance was automatically recorded at 5 second intervals at MS1-MS3, and 1 min 
intervals at "Background". The background specific conductance remained relatively constant during each experiment with changes less than $2 \mu \mathrm{S} / \mathrm{cm}$. The average of the background specific conductance was subtracted from the tracer breakthrough curves at the three monitoring stations, before parameter estimation. We calculated channel flow rate using specific conductance values at MS1 after specific conductance had plateaued and assuming complete recovery of tracer.

\subsection{Transient Storage Modeling and Data Analysis}

We analyzed our conservative tracer data using the one dimensional advection dispersion equation with exchange with a well-mixed off-channel transient storage zone, as described in Bencala and Walters (1983). The model is known as the transient storage model (TSM) and is implemented in the software OTIS:

$$
\begin{gathered}
\frac{\partial C}{\partial t}=-\frac{Q}{A} \frac{\partial C}{\partial x}+\frac{1}{A} \frac{\partial}{\partial x}\left(A D \frac{\partial C}{\partial x}\right)-\alpha(C-S) \\
\frac{\partial S}{\partial t}=\alpha \frac{A}{A_{s}}(C-S)
\end{gathered}
$$

where $C$ and $S$ are solute concentration $\left[\mathrm{ML}^{-3}\right]$ in the main channel and in the transient storage zone, respectively; $t$ is time [T], $A$ and $A_{s}$ are cross-sectional areas $\left[\mathrm{L}^{2}\right]$ of the main channel and the transient storage zone, respectively; $Q$ is the stream channel flow rate $\left[\mathrm{L}^{3} \mathrm{~T}^{-1}\right] ; D$ is the dispersion coefficient $\left[\mathrm{L}^{2} \mathrm{~T}^{-1}\right] ; x$ is the distance downstream of the injection $[\mathrm{L}]$, and $\alpha$ is the exchange rate coefficient $\left[\mathrm{T}^{-1}\right]$ with the transient storage zone.

We used the inverse modeling version of the OTIS software known as OTIS-P (Runkel, 1998), to estimate the transport parameters $D, A, A_{s}$ and $\alpha$. Transport parameters for the control 
reach (MS1-MS2) were estimated by fitting modeled specific conductance (SPC) to observed SPC at MS2, using observed SPC at MS1 as the upstream boundary condition. Similarly, parameters for the treatment reach (MS2-MS3) were estimated by fitting modeled SPC to observed SPC at MS3, using observed SPC at MS2 as the upstream boundary conditions. Even though the two reaches are contiguous, natural variability between the reaches made direct comparison of transport parameters difficult. We therefore, calculated the percent change in each parameter (during E2 through E6) relative to their initial values during E1, and compared those between the two reaches. This approach better distinguishes the impact of the weirs on the transport parameters. Identical changes in the control reach and treatment reach parameter values would imply that the weirs did not have measurable impact on the estimates of the transport parameters. We also report the propagated $95 \%$ confidence interval (CI) of the normalized transport parameters. The actual 95\% CI was obtained from OTIS-P, which uses the non-linear regression routine STARPAC to calculate the approximate variance of the parameters in the vicinity of the parameter estimate (Runkel 1998).

We calculated the Damköhler ( $\mathrm{Dal}$ ) [--] number to assess the suitability of the length of the two reaches for transient storage parameter estimation (Wagner and Harvey, 1997):

$$
D a l=\alpha\left(1+\frac{\mathrm{A}}{\mathrm{A}_{\mathrm{s}}}\right) \frac{L}{u}
$$

where, $L$ is the length [L] of the reach and $u$ is the average stream velocity $\left[\mathrm{LT}^{-1}\right]$, calculated as $Q / A$. We also calculated the metric $F_{\text {med }}^{200}[--]$ (Runkel, 2002), defined as the fraction of median travel time $\left(t_{n}\right)$ attributable to the retention caused by exchange with transient storage, for a standardized reach of $200 \mathrm{~m}$. Median travel time, $t_{n}$, for a reach is the time required for half the 
tracer molecule (from a pulse injection) to pass the downstream end of the reach, which can be approximated for a constant rate injection by measuring the time elapsed for the achievement of half of the plateau concentration. The metric $F_{m e d}^{200}$ incorporates the role of advective and nonadvective movement of water and mass in the reach travel time calculation and was calculated using the approximate function presented in Runkel (2002):

$$
F_{m e d}^{200} \approx\left(1-e^{-L \frac{\alpha}{u}}\right) \frac{A_{S}}{A+A_{S}}
$$

\subsection{Statistical Analysis}

To analyze the impact of the weirs on the transport parameters, first we calculated the percentage change in the transport parameters, $\Delta p_{i}$ from their initial values (i.e. E1) for each experiment and reach (i.e., $\left.\Delta p_{i}=\left(p_{i}-p_{E 1}\right) / p_{E 1}, i=\mathrm{E} 2, \ldots \mathrm{E} 6\right)$. Weirs were added in stages in the treatment reach but nothing changed besides flow in the control reach. Then, we tested the null hypothesis that the changes in parameter values (with respect to their values from E1) were identical in both reaches, using Student's t distribution. This is identical to testing the hypothesis that a set of samples $d_{i}$ is t-distributed with a population mean of zero and standard deviation equal to sample standard deviation, where $d_{i}=\Delta p_{i, \text { cont }}-\Delta p_{i, \text { treat }}, i=E 2, \ldots E 6$. Identical changes in control and treatment reach parameter values (i.e., $d_{i}$ indeed has a mean of zero), will imply that the weirs did not have measurable impact on the parameter values. A high p-value indicates support for the null hypothesis, whereas a low p-value indicates insufficient evidence to support the null hypothesis.

\section{Results}

\subsection{Flow Variation}


Our experiments had two principal independent variables, the number of weirs and stream flow $(Q)$. Even though we had control over the number of weirs, $Q$ variation was uncontrolled and followed the seasonal recession trend. During the 29-day experimental period, channel flow (Q) dropped by $70 \%$ (from $14.6 \mathrm{~L} / \mathrm{s}$ to $4.4 \mathrm{~L} / \mathrm{s}$, Table 1 ). This variability in $Q$ was relatively low compared to the full annual range (as represented by variation in measured stream stage, Figure 2). Although we assumed constant $Q$ during each individual experiment, $Q$ actually varied over the course of each experiment, primarily due to the diel cycle of evapotranspiration. The two experiments with the lowest $Q$ (E4 and E6) had the highest relative sub-daily $Q$ variability (4.4 and $11.4 \%$, respectively, Figure 3). For the rest of the experiments, $Q$ variation was $2.1 \%$ or less. This sub-day variability for E4 and E6 also manifested in the breakthrough curves (BTC) in the form of an upward sloping specific conductance plateau (Figure 4d, f).

\subsection{Transport Parameters}

\subsubsection{Effect of Channel-Spanning Structures}

We focus in this section on experiments E1 through E4, where the number of weirs was successively increased from 0 to 10 (Table 1). Streamflow $(Q)$ also decreased during the first four experiments, and since $Q$ can have significant impact on solute transport, we also discuss how such variation in $Q$ can explain some of the observed variation in transport parameters during these first 4 experiments. We focus on trends of transport parameters relative to the first experiment (E1) (Figure 5) rather than the absolute differences among reaches, although the latter is available in Table 2.

The dispersion coefficient $(D)$ decreased both in the control and treatment reaches with the greatest drop occurring from E1 to E2 (Figure 5a). The decrease was slightly greater in the 
treatment reach, but this was not statistically significant $(p-v a l u e=0.14)$. Dispersion coefficient is often estimated as function of average velocity $(u)$, and also square of $u$ (Chapra, 1997). The trend of $D$ with $u$ (Figure 6a) was approximately linear for the treatment reach.

Channel flow cross-sectional area $(A)$ in the treatment reach increased approximately linearly with increasing number of weirs, despite simultaneously decreasing $Q$ (experiment E2, E3 and E4, Figure 5b). By contrast, $A$ decreased across the experiments in the control reach, and was significantly different (p-value of 0.003 ) than in the treatment reach. Transient storage zone cross sectional area $\left(A_{s}\right)$ for the treatment reach monotonically increased during the first four experiments except for E3 and ranged between approximately 125 and 190\% of the first experiment (p-value of 0.006 , Figure 5c). In the control reach $A_{s}$ oscillated among different experiments with perhaps a small increasing trend, ranging from 11 to $72 \%$ of the first experiment. The transient storage exchange rate coefficient $(\alpha)$ decreased in both reaches, but the decrease was significantly higher in the treatment reach ( $\mathrm{p}$-value $=0.004$, Figure $5 \mathrm{~d}$ ).

The ratio $A_{s} / A$ generally increased in the control reach due to increases in $A_{s}$ and simultaneous decreases in $A$ (Figure 5e). Similarly, $A_{s} / A$ increased in the treatment reach as an increase in $A$ (maximum increase of about $75 \%$ ) was overwhelmed by the relatively larger increase in $A_{s}$ (maximum increase of about 240\%). Despite the substantial increase in $A_{s}$ in the treatment reach, the simultaneous increase in $A$ in the treatment reach led to moderate increases in $A_{s} / A$. In the two reaches, changes in $A_{s} / A$ were not significantly different (p-value $=0.93$ ).

To account for the effect of changes in $Q$, and therefore to isolate the effects of the different treatments, we normalized the treatment reach parameter with the control reach parameter (Figure 5f). Dispersion decreased in the treatment reach from about $90 \%$ to $40 \%$ of its value in 
the control reach, $A$ increased from about $80 \%$ to about $150 \%, A_{s}$ oscillated (but generally increased with the number of weirs) and ranged between $30 \%$ and $80 \%$, and $\alpha$ decreased from about 80 to 40\%. These trends confirm the trends seen in Figures 5a-d.

$F_{\text {med }}^{200}$ increased in both reaches by $\sim 160 \%$ (Table 2, Figure $7 \mathrm{a}$ ) indicating no significant difference for weirs. On the other hand, the addition of weirs substantially increased the median travel time $\left(t_{n}\right)$ in the treatment reach $(\sim 325 \%)$ relative to the control reach $(\sim 125 \%)$ (Figure 7b). Except for the first experiment, $t_{n}$ was higher in the treatment reach for all experiments and increased with the number of weirs (Table 2). The absolute values of the part of $t_{n}$ attributable to transient storage (estimated by multiplying $t_{n}$ and $F_{\text {med }}^{200}$ ) were higher for the control reach for all experiments. However, the changes in this parameter relative to the first experiment were larger in the treatment reach than in the control reach (Figure 7c).

\subsubsection{Effect of Flow Variation}

Since flow $Q$ was the main independent variable in the control reach, delineating the effect of $Q$ variation in the control reach is straightforward. By contrast, coupled changes in both $Q$ and number of weirs in the treatment reach make the interpretation of the impact of $Q$ more difficult for experiments E1 through E3 (Table 1). Hence, for the treatment reach we primarily focus on the last three experiments, E4 through E6, when the number of weirs was not changing. Nevertheless, we do gain insight where we can from the changes observed in E1 through E3, conscious of the fact that the number of weirs was not constant but rather gradually increasing, with the control reach observations helping us to partially isolate the effects of $Q$. 
In the control reach, $A$ and $\alpha$ had a clear positive correlation with $Q$ across all six experiments (Figure 8a, c), while $A_{s}$ was negatively correlated (Figure 8b). $D$ in the control reach was positively correlated with $Q$ (Figure $8 \mathrm{~d} ; r=0.84$ ), although this correlation clearly depended on the large value of $D$ from E1 (Figure 8d) and exclusion of this data point would make the correlation slightly negative.

In the treatment reach, during the last three experiments (E4-E6), changes in $A_{s}$ and $\alpha$ differed from that in the control reach (Figure 8). By contrast, trends in $A$ and $D$ were similar in both reaches during these experiments. Changes in $\alpha$ and $D$ with $Q$ were milder in the treatment reach than in the control reach during E4 through E6. By contrast, in the first three experiments (E1-E3, when numbers of weirs varied), $A$ increased with concurrent decreases in $Q$ in the treatment reach. Transient storage area, $A_{s}$, increased both in the control reach and the treatment reach during E1 through E3, but the increase was relatively higher in the treatment reach. Both $\alpha$ and $D$ decreased in the two reaches during the first three experiments, but the rate of change was steeper in the treatment reach. The trends of transport parameters with $Q$ show consistent behavior in the control reach but no such consistent trend was observed in the treatment reach. Overall, Figure 8 shows how most parameter trends with $Q$ were altered by the weirs.

\subsection{Parameter Reliability}

Experimental Damköhler number ( Dal) is an indicator of the reliability of the estimated transient storage parameters and ideally should be 1.0, but a range that is considered reasonable is between 0.5 and 5 (Harvey and Wagner, 2000). For the control reach, Dal ranged between 0.40 and 0.64 while for the treatment reach Dal ranged between 0.43 and 0.84 (Table 3). In 
general, the treatment reach had slightly better Dal (average of 0.68) than the control reach (average of 0.54). The only Dal less than 0.5 were for the treatment reach for E5 and the control reach for E6. Wagner and Harvey (1997) suggested designing experiments based on Dal, but it was impractical for us to change reach lengths with $Q$ given the type of manipulations we performed. Nevertheless, Dal of the different experiments gives us a metric to weigh the results of each experiment according to their respective reliability. In terms of model fitness, the modeled tracer BTC matched the observed data well (Figure 4) for all experiments except for E4 and E6. The mean squared residuals (total squared residuals normalized by number of observation) were less than 2 for all experiments, except for E4 (around 4.5 for the two reaches) and E6 (around 6) (Table 3).

\section{Discussion}

\subsection{Effect of Channel-Spanning Stream Restoration Structures}

\subsubsection{Effect on Transport Parameters}

Weir construction creates obstruction to flow and dissipates energy, changing local flow conditions and in turn affecting solute transport locally and potentially downstream. The parameters of the one dimensional transient storage model give a highly simplified representation of the actual processes that solutes undergo. Yet the transient storage model gives us valuable (albeit implicit) information as to the fate and transport of solutes. Here we refer to the latter effect as reach scale transport effects. The most important effect of the weirs that we observed was the reduction of channel flow velocity due to added resistance from the weirs, which subsequently caused an increase in channel flow cross-sectional area, $A$. The increase in $A$ 
can be understood by applying a uniform open channel flow equation at the reach scale (i.e.

encompassing multiple weirs). For example, in the Manning's equation $\left(Q=n^{-1} R^{2 / 3} S_{0}^{1 / 2} A\right)$, weirs would increase the roughness coefficient $n$ (consequently increasing $A$ to route the same $Q$, assuming slope $S_{0}$ remains constant).

The increase in $A$ from the addition of weirs in turn led to a decrease in $u$, which in turn would explain the associated decrease in exchange rate parameter $\alpha$ (Figure 6b). Average stream velocity is also positively correlated with $Q$ and therefore we also observed lowering of $\alpha$ in the control reach over time. Positive correlation between $\alpha$ and $u$ has been observed in multiple prior studies collated by Johnson et al. (2014). Reduced $u$ decreases exchange with surface transient storage through decreased turbulence (D’Angelo et al., 1993; Phanikumar et al., 2007). In terms of hyporheic transient storage, reduction in $u$ leads to reduced turbulent hyporheic exchange with the shallowest/coarsest sediments (Nagaoka and Ohgaki, 1990; Elliott and Brooks, 1997; Packman and Brooks, 2001; Boano et al., 2011; Blois et al., 2014), and also reduced form-drag induced hyporheic exchange by ripples, dunes, and bars (D'Angelo et al., 1993; Zarnetske et al., 2007; Jin et al., 2009). By contrast, dispersion was less sensitive to stream manipulation than the other transport parameters. Still, the modest observed decline in $D$ (Figure 5a) most likely was due to the reduction of turbulent diffusion and therefore reduction in longitudinal plume spreading as $u$ decreased (e.g., Ward et al., 2013). Contrary to our observation, Becker et al. (2013) reported increases in velocity and $\alpha$ in reaches restored using natural channel design method (Rosgen, 1994). Even though their flow obstructing structures also created pools, the authors attributed increased flow velocity to the reduced conveyance area around restoration 
structures. Thus their structures may have had different impacts to surface water hydraulics, with corresponding transient storage effects.

Increases in both the number of weirs and $Q$ in our study appeared to lead to increases in the size of the transient storage zone $A_{s}$, probably due to increased surface transient storage volume behind the weirs and increased volume of hydrostatically driven hyporheic flow paths beneath the weirs. These effects are consistent with increases in surface dead zones (a contributor to surface transient storage, Ensign and Doyle, 2005; Roberts et al., 2007; Jin et al., 2009) and hyporheic flow paths (e.g., Azinheira et al., 2014, Hester and Gooseff, 2011, Hester et al., 2009) due to in-stream structures as reported in the literature. Nevertheless, $A_{s} / A$, which is often considered an indicator of the potential of the transient storage to impact solute transport/processing (Runkel 2002), increased in both reaches (Figure 5e), such that there was little comparative increase in the treatment reach (Figure 5f). In other words, the relatively significant increase in $A_{s}$ was masked by the concurrent increase in $A$, which supports the contention by Runkel (2002) that these parameters cannot be used on their own to compare different reaches (or streams) without simultaneously accounting for other parameters, such as $\alpha$ and $u$. The simultaneous increase in $A_{s}$ and decrease in $\alpha$ with weir installation may cancel each other out in terms of net effect on pollutant or nutrient processing. While increased $A_{S}$ is considered beneficial for solute processing, a decrease in $\alpha$ can be interpreted as both advantageous and disadvantageous (Runkel, 2002). For example, as $\alpha$ decreases, the metric representing average flux through storage zone per unit length, $q_{s}(=\alpha A)$, decreases. On the other hand, the metric representing average time in storage, $T_{\text {sto }}\left(=A_{s} \alpha^{-1} A^{-1}\right)$, will increase. 
Median travel time $t_{n}$ is not affected by extreme values, and provides another perspective of how transient storage affects solute transport. We partitioned median travel into two parts, one that is due to main channel transport and the other due to transient storage. The increase in $t_{n}$ could be explained by the increase in surface transient storage area (with relatively low exchange) and increased hydrostatically driven hyporheic exchange near the weirs. At the same time that the weirs were installed, $Q$ also decreased due to seasonal recession, which would also increase $t_{n}$ due to lowered $u$ in the channel, as observed in the control reach. Yet, the greater increase in $t_{n}$ in the treatment reach where there were also increases transient storage (Figure 7c) shows that solutes are being retained longer where weirs are present.

An increase in $t_{n}$ due to transient storage would be potentially beneficial in terms of time available for solute processing. However, the importance of this enhanced retention depends on whether it is surface or subsurface storage (Stewart et al., 2011; Gomez-Velez et al., 2015), in that surface processing can be quite slow compared to that in the sediment or hyporheic zone (Hall et al., 2002; Haggerty et al., 2008; Hester and Gooseff, 2010, 2011). We surmise that the weirs caused a switch from short hyporheic flow paths through shallow coarse sediment, due to turbulence and form drag over ripples (which would give low $A_{s}$ and high $\alpha$ ), to sluggish exchange with dead zones on the surface and some longer hyporheic flow paths induced by hydrostatic head drop over weirs (which would give high $A_{s}$ and low $\alpha$, with higher likelihood to remain undetected by the current tracer method due to its limited window of detection). Thus, in order for weir installation to achieve net improvement in water quality, cumulative processing in the backwater surface transient storage zones behind weirs and greater hydrostatically induced hyporheic exchange around weirs would have to overcome the loss of processing capacity from 
reduced hydrodynamically induced hyporheic exchange and surface dead zone exchange rate. This is consistent with recent studies which show that cumulative hyporheic exchange through smaller geomorphic forms (e.g., ripples) can be greater than that induced by larger structures such as weirs (Gomez-Velez and Harvey, 2014; Gomez-Velez et al., 2015).

The transient storage model is relatively less representative of deeper hyporheic fluxes, due to the limited window of detection of the tracer method, such that the longer portion of the hyporheic flow paths created by the weirs might have remained "unobserved" (Zaramella et al., 2003; Briggs et al., 2009; Ward et al., 2013b). Deeper hyporheic flow paths are often less important than relatively shallow hyporheic exchange, due to their low flow rate (hence, low reactant delivery) compared to the stream flow (Gomez-Velez and Harvey, 2014; Gomez-Velez et al., 2015). Hence, the longer time scale exchanges that weirs enhance most likely have lower impact on solute processing. Depending on geology, deeper hydraulic flow paths could become constrained due to bed rock and in extreme eliminate hyporheic flow entirely. Streams with minimal hyporheic exchange could potentially benefit relatively more from any surface transient storage induced by weirs.

\subsubsection{Implications for Stream Restoration}

Reduction in $u$ by channel-spanning structures can be consequential for stream restoration since any gain in $A_{s}$ might ultimately be overcome by the effect of lower $\alpha$. Stewart et al. (2011) illustrated that the relative importance of $A_{s}$ and $\alpha$ is determined by the biological/chemical process being considered where a highly reactive process (e.g., chemical oxidation) will be controlled by $\alpha$ and a less reactive process (e.g., denitrification) will be controlled by the size of 
$A_{s}$. Reducing $u$ with flow obstructing structures might shift the spatial structure of transient storage giving more importance to less reactive surface transient storage and less importance to highly reactive hyporheic transient storage (although some reactions like photochemical breakdown is only possible on the surface). Simultaneously, within the hyporheic transient storage, we may be shifting from shorter residence time hydrodynamically-induced hyporheic transient storage that favors rapid reactions to longer residence time hydrostatically-induced hyporheic transient storage that favors slower reactions. This shift toward longer residences times may in turn increase the fraction of hyporheic flow paths that experience anoxia and hence reactions that are enhanced in such conditions, e.g., denitrification. Nevertheless, conclusions drawn from this stream might not be generally applicable to other streams because hyporheic exchange is heavily controlled by geology (Baker et al., 2012, Zarnetske et al., 2007). Our study therefore highlights the importance of assessing each stream separately when evaluating the impact of reach scale restoration.

Our results also illustrate the need for methods that are capable of reliably separating surface transient storage from hyporheic transient storage and the need to consider the impact of restoration structures on surface and hyporheic transient storage separately (Briggs et al., 2010). It is possible that an optimum condition exists where hyporheic transient storage lost from reduced hydrodynamic exchange can be overcome by increased hydrostatic exchange but evaluation of such optimal condition is not possible using the conservative tracer method employed here. Additional information from reactive tracer (e.g., Argerich et al., 2011) or subsurface sampling (e.g., Harvey et al., 2012, 2013; Stonedahl et al., 2012; Zimmer and Lautz, 2015) might aid in separating the impact on surface and hyporheic transient storage. 


\subsection{Effect of Flow Variation}

\subsubsection{Effect on Transport Parameters}

The trends of transient storage parameters with $Q$ in the control reach (Figure 8) were not surprising, as similar observations have also been reported in the literature (e.g., Schmid et al., 2010). Of the various parameters in the treatment reach, stream cross-sectional area $(A)$ in particular behaved similarly to the control reach, increasing with $Q$ when the number of weirs was held constant.

However, for some parameters, we observed markedly different responses to $Q$ in the treatment reach. For example, the general trend of decreasing $A_{S}$ with increasing $Q$ in the absence of weirs, i.e. in the control reach from E1 through E6 and to some extent in the treatment reach during E1 through $\mathrm{E} 4$, can be explained by surface transient storage zones being relatively smaller compared to the channel cross sectional area during higher flows. By contrast, the opposite trend of increasing transient storage area $\left(A_{S}\right)$ with increasing $Q$ observed in the treatment reach during E4 through E6 might be explained by higher flows creating larger pools behind the weirs. Dynamic hyporheic transient storage should increase with $Q$ in the control reach, but this was not sufficient to overcome the loss in surface transient storage area in the control reach.

The minimal change in exchange rate $(\alpha)$ with decreasing $Q$ (and hence $u$ ) in the last three experiments (E4 through E6) in the treatment reach compared to the control reach (Figure 8c) is most likely due to the fact that $\alpha$ has already been reduced extensively by the drop in velocity near the weirs, such that it has become less responsive to further lowering of $u$. As can 
be seen from the trend in the control reach, $\alpha$ is strongly nonlinear with $Q$ (i.e., $u$ ) with a stronger relationship/steeper trend at lower $Q$. By contrast, in the treatment reach, weir-induced backwater strongly suppressed $\alpha$, which is an order of magnitude less than in the control reach (Table 2), and became less responsive to further change in $Q$ during E4 through E6. Gradual addition of weirs directed $\alpha$ towards this less responsive state, as seen from E1 through E3.

The observed change in parameter response to flow variation in presence of weirs is most likely due to the nature of the resistance provided by the weirs. Unlike channel perimeter roughness, weirs provide point roughness and create large pools that dissipate energy via sudden expansion. An analogous situation for weirs in piped flow would be a large minor loss due to sudden expansion at pipe junctions, whereas channel roughness would be analogous to pipe roughness. Our three experiments with constant number of weirs are not statistically definitive, yet our results do suggest that transport parameters of stream reaches with dense channel spanning weirs might respond differently to $Q$ variation than reaches without them.

More fundamentally, our work shows the complication of dealing with $Q$ variability in analyzing transient storage data. Unless $Q$ variability can be eliminated, there will always be conflation of observed changes in transient storage parameters among experimental treatments with changes in $Q$. From this perspective our $Q$ variability was at an annual minimum (represented by variation in stream stage, Figure 2) and therefore unusually well suited for such experiments yet $Q$ still declined by $\sim 70 \%$ over the course of our six experiments. Given that it is impossible to predict $Q$ variability ahead of time with any accuracy, it is reasonable to assume that our relatively low $Q$ variation is not easily repeatable, and our site is not unique in this regard. This joins earlier concerns expressed about the sensitivity of the transient storage 
approach to $Q$ variation (Harvey et al., 1996; Wondzell, 2006; Ward et al., 2013b) and warrants caution. Harvey et al. (1996) in particular found that with increasing $Q$ the transient storage model becomes increasingly insensitive to hyporheic exchange due to the shrinking of window of detection at high $u$. In our treatment reach, shorter/faster hydrodynamically driven hyporheic flow paths were likely reduced by the weirs, while longer hydrostatically driven hyporheic flow paths were likely enhanced. Any shift toward hydrostatically induced hyporheic exchange could yield a reduction in ability of the transient storage approach to fully characterize that exchange, complicating the comparison between different experiments. These issues may have ramifications beyond physical hydrology. For example, Ye et al. (2012) coupled a hydrologic model with the transient storage model to compute nitrogen retention in river networks with assumed transient storage parameters. The uncertainties discussed here would have produced uncertainties in the estimates of nitrogen retention.

Flow variation was also evident during individual experimental days from the upward sloping plateaus of most BTCs, particularly E4 and E6 (Figure 4). We expect that this was mostly due to evapotranspiration during daylight hours. This led to a poorer fit (Table 3) of the modeled transport for E4 and E6 compared to the rest of the experiments. Such non-ideal flow conditions meant greater uncertainty in the parameter estimation of E4 and E6 but from inspection of the plots we conclude that the uncertainty is well within the bounds that is typical in transient storage model literature, and regardless does not impact our conclusions.

\subsubsection{Implications for Stream Restoration}


The high sensitivity of the transient storage approach to $Q$ variation raises a potential quandary for assessing the water quality impacts of stream restoration. Quite a bit of trust has been placed in stream restoration to play a significant role (e.g., in reducing nutrient pollution to Chesapeake Bay, Berg et al., 2014), and practitioners are already widely using this approach. Yet these existing approaches are generally silent on how much specific stream restoration practices will reduce water quality impairment or pollutant loading, and how that varies in time and space (Veraart et al., 2014). In the case of in-stream structures, an example question is how many structures are needed to remove $50 \%$ of the excess N? And how does that vary with parameters such as $\mathrm{N}$ concentration, channel slope, and of course stream channel flow rate? The transient storage approach has significant appeal in quantitatively testing the efficacy of these BMPs because it is relatively quick and inexpensive, yet still integrates the net effect of a whole reach into a single quantification. This contrasts with point measurements such as hyporheic piezometers. Yet the main weakness of the transient storage approach is that $Q$ variation affects the answers substantially even when $Q$ variation is minimized as much as is reasonably possible. For example, a recent study by Mueller Price et al. (2016) observed that nitrogen removal capacity gained by stream restoration/manipulation can potentially be overwhelmed by flow variation. These issues can be addressed to some extent using control reaches and duplicate experiments over time as we have, but these techniques substantially increase the data collection effort in both time and space. Thus, there is great incentive for future development and improvements in this area, for both scientific and applied reasons.

\section{Conclusions}


There is increased interest in stream restoration for its potential to improve water quality. In this study we tested the effect of common in-stream restoration structures (weirs representing channel-spanning structures such as log dams and boulder weirs), in a small forested stream. We tested their impact on transient storage in surface dead zones and the hyporheic zone, as measured by constant rate injection of conservative tracer. We experimentally added 10 weirtype structures along an $80 \mathrm{~m}$ reach and compared the effects with an un-manipulated control reach.

The weirs significantly increased channel flow cross-sectional area $(A)$ due to creation of backwater. The weirs also enhanced cross-sectional area of the transient storage zone $\left(A_{s}\right)$, likely both in surface water (backwater behind weirs) and in the hyporheic zone (due to the induced hydrostatic gradient across the weirs), although the transient storage modeling approach cannot distinguish these components. Simultaneous with an increase in $A_{s}$ was a decrease in exchange rate with the transient storage zone $(\alpha)$ thus making the overall impact of the weirs on water quality complicated. The reduction in $\alpha$ is likely due to the increase in $A$ which increases residence time in the reach $\left(t_{n}\right)$ and reduces channel flow velocity $(u)$. Reduced $u$ reduces hydrodynamically driven hyporheic exchange due to reduced turbulence and form drag across existing bedforms such as ripples, and similarly reduces exchange with surface transient storage due to reduced turbulence. The impact of increased hydrostatically driven hyporheic exchange by the weirs was either overcome by the losses in hydrodynamically driven exchange or was "unobserved" due to the limited window of detection of the tracer method. Our results are thus consistent with weirs causing a switch from short fast moving hydrodynamically driven hyporheic flow paths through shallow coarse sediment (which would give low $A_{s}$ and high $\alpha$ ) to 
long slow moving hydrostatically driven hyporheic flow paths (which would give high $A_{s}$ and low $\alpha)$.

These results have substantial implications for efforts to harness in-channel stream restoration structures to improve water quality. The various effects of these structures are complicated and potentially mutually cancelling, such that assuming greater connectivity with hyporheic zones from instream structures (e.g., cross-vanes or J-hooks) may not have the intended water quality effect.

Our results also provide a series of methodological insights. We emphasize the importance of the effect of channel flow rate $(Q)$ variation on transient storage. Exchange rate, $\alpha$, increased with $u$ and hence $Q$ in both control and treatment reaches. On the other hand, the trend of $A_{s}$ with $Q$ was different in the treatment reach than in the control reach, even with constant number of weirs. This may explain contradictory results in the literature that show both increases and decreases in transient storage characteristics in response to spatial and temporal variations in $Q$. Nevertheless, despite natural $Q$ variation affecting our experimental results, we actually minimized such variation as much as possible, underlining the challenges of generating definitive data on the water quality effects of in-channel stream restoration practices using the transient storage model. This also emphasizes that hyporheic exchange (and consequently capacity for water quality reactions) is highly variable across time, and evaluation of stream restoration projects at one flow regime most likely cannot be used to estimate the aggregate effect across time. Even though the transient storage model is widely to analyze solute transport, it alone cannot provide sufficient information about potential of stream restoration structures for water quality benefit. 
In summary, using channel-spanning stream restoration structures could be promising in enhancing transient storage, but additional study is needed to sort out the mechanisms behind observed changes in transient storage model parameters. An optimal condition might exist that maximizes increases in $A_{s}$ and minimizes decreases in $\alpha$, which is an interesting topic for future research.

\section{Acknowledgements}

The authors thank the Virginia Tech College of Engineering for support to S. Rana. The authors thank NSF for support under grant NSF-ENG-1066817. The opinions expressed are those of the authors and not necessarily those of the NSF. The authors thank the various field helpers for their assistance during the experiments.

\section{References}

Argerich A, Haggerty R, Marti E, Sabater F, Zarnetske J, Martí E. 2011. Quantification of metabolically active transient storage (MATS) in two reaches with contrasting transient storage and ecosystem respiration. Journal of Geophysical Research-Biogeosciences 116 (G3): G03034 DOI: 10.1029/2010jg001379

Arrigoni AS, Poole GC, Mertes LAK, O’Daniel SJ, Woessner WW, Thomas SA. 2008. Buffered, lagged, or cooled? Disentangling hyporheic influences on temperature cycles in stream channels. Water Resources Research 44 (9): W09418

Azinheira DL, Scott DT, Hession W, Hester ET. 2014. Comparison of effects of inset floodplains and hyporheic exchange induced by in-stream structures on solute retention. 
Water Resources Research 50 (7): 6168-6190

Baker DW, Brian PB, Price JM. 2012. Stream nitrate uptake and transient storage over a gradient of geomorphic complexity, north- central Colorado, USA. Hydrological Processes 26 (21): $3241-3252$.

Baron JS, Poff NL, Angermeier PL, Dahm CN, Gleick PH, Hairston Jr NG, Jackson RB, Johnston CA, Richter BD, Steinman AD. 2002. Meeting ecological and societal needs for freshwater. Ecological Applications 12 (5): 1247-1260

Becker JF, Endreny TA, Robinson JD. 2013. Natural channel design impacts on reach-scale transient storage. Ecological Engineering 57: 380-392.

Bencala KE, Walters RA. 1983. Simulation of solute transport in a mountain pool-and-riffle stream: A transient storage model. Water Resources Research 19 (3): 718-724 DOI: 10.1029/WR019i003p00718

Bencala KE, McKnight DM, Zellweger GW. 1990. Characterization of transport in an acidic and metal-rich mountain stream based on a lithium tracer injection and simulations of transient storage. Water Resources Research 26 (5): 989-1000

Berg J, Burch J, Cappuccitti D, Filoso S, Fraley-mcneal L, Goerman D, Hardman N, Kaushal S, Medina D, Meyers M, et al. 2014. Recommendations of the Expert Panel to Define Removal Rates for Individual Stream Restoration Projects. Ellicott City.

Bernhardt ES, Likens GE, Buso DC, Driscoll CT. 2003. In-stream uptake dampens effects of major forest disturbance on watershed nitrogen export. Proceedings of the National Academy of Sciences 100 (18): 10304-10308

Bernhardt ES, Likens GE, Hall RO, Buso DC, Fisher SG, Burton TM, Meyer JL, McDowell 
WH, Mayer MS, Bowden WB, et al. 2005. Can't see the forest for the stream? In-stream processing and terrestrial nitrogen exports. Bioscience 55 (3): 219-230

Bhuiyan F, Hey RD, Wormleaton PR. 2007. Hydraulic evaluation of W-weir for river restoration. Journal of Hydraulic Engineering 133 (6): 596-609

Bilby RE, Likens GE. 1980. Importance of organic debris dams in the structure and function of stream ecosystems. Ecology: 1107-1113

Blois G, Best JL, Sambrook Smith GH, Hardy RJ. 2014. Effect of bed permeability and hyporheic flow on turbulent flow over bed forms. Geophysical Research Letters 41 (18): $6435-6442$

Boano F, Revelli R, Ridolfi L. 2011. Water and solute exchange through flat streambeds induced by large turbulent eddies. Journal of Hydrology 402 (3): 290-296

Breitburg DL, Sanders JG, Gilmour CC, Hatfield CA, Osman RW, Riedel GF, Seitzinger SP. 1999. Variability in responses to nutrients and trace elements, and transmission of stressor effects through an estuarine food web. Limnology and Oceanography 44 (3part2): 837-863

Briggs M a., Lautz LK, Hare DK, González-Pinzón R. 2013. Relating hyporheic fluxes, residence times, and redox-sensitive biogeochemical processes upstream of beaver dams. Freshwater Science 32 (2): 622-641 DOI: 10.1899/12-110.1

Briggs MA, Gooseff MN, Arp CD, Baker MA. 2009. A method for estimating surface transient storage parameters for streams with concurrent hyporheic storage. Water Resources Research 45 (4)

Briggs MA, Gooseff MN, Peterson BJ, Morkeski K, Wollheim WM, Hopkinson CS. 2010. Surface and hyporheic transient storage dynamics throughout a coastal stream network. 
Water Resources Research 46 (6) DOI: 10.1029/2009WR008222

Brooks AP, Gehrke PC, Jansen JD, Abbe TB. 2004. Experimental reintroduction of woody debris on the Williams River, NSW: geomorphic and ecological responses. River Research and Applications 20 (5): 513-536

Bukaveckas PA. 2007. Effects of channel restoration on water velocity, transient storage, and nutrient uptake in a channelized stream. Environmental science \& technology 41 (5): 15701576

Chapra, S.C., 1997. Surface Water Quality Modeling. McGraw-Hill, New York City, New York.

Craig LS, Palmer M a, Richardson DC, Filoso S, Bernhardt ES, Bledsoe BP, Doyle MW, Groffman PM, Hassett B a, Kaushal SS, et al. 2008. Stream restoration strategies for reducing river nitrogen loads. Frontiers in Ecology and the Environment 6 (10): 529-538 DOI: $10.1890 / 070080$

D’Angelo ADJ, Webster JR, Gregory S V, Meyer JL. 1993. Transient storage in Appalachian and Cascade mountain streams as related to hydraulic characteristics. Journal of the North American Benthological Society 12: 223-235 DOI: 10.2307/1467457

Daniluk TL, Lautz LK, Gordon RP, Endreny TA. 2013. Surface water--groundwater interaction at restored streams and associated reference reaches. Hydrological Processes 27 (25): $3730-3746$

Doll BA, Grabow GL, Hall KR, Halley J, Harman WA, Jennings GD, Wise DE. 1999. Stream restoration: a natural channel design handbook. North Carolina Stream Restoration Institute.

van Driel PW, Robertson WD, Merkley LC. 2006. Denitrification of agricultural drainage using 
wood-based reactors. Transactions of the ASAE 49 (2): 565-574

Elliott AH, Brooks NH. 1997. Transfer of nonsorbing solutes to a streambed with bed forms:

Theory. Water Resources Research 33 (1): 123-136

Ensign SH, Doyle MW. 2005. In-Channel Transient Storage and Associated Nutrient Retention:

Evidence from Experimental Manipulations. Limnology and Oceanography 50 (6): 1740_

1751 DOI: $10.2307 / 3597917$

FISRWG. 1998. Stream corridor restoration: principles, processes, and practices. Federal

Interagency Stream Restoration Working Group (FISRWG)(15 Federal agencies of the US gov’t). Available at: http://go.usa.gov/BvNA

Fuller CC, Harvey JW. 2000. Reactive Uptake of Trace Metals in the Hyporheic Zone of a Mining-Contaminated Stream, Pinal Creek, Arizona. Environmental Science \& Technology 34 (7): 1150-1155

Gomez-Velez JD, Harvey JW. 2014. A hydrogeomorphic river network model predicts where and why hyporheic exchange is important in large basins. Geophysical Research Letters $\mathbf{4 1}$ (18): 6403-6412

Gomez-Velez JD, Harvey JW, Cardenas MB, Kiel B. 2015. Denitrification in the Mississippi River network controlled by flow through river bedforms. Nature Geoscience

Gordon RP, Lautz LK, Daniluk TL. 2013. Spatial patterns of hyporheic exchange and biogeochemical cycling around cross-vane restoration structures: Implications for stream restoration design. Water Resources Research 49 (4): 2040-2055 DOI: 10.1002/wrcr.20185

Haggerty R, Argerich A, Martí E, Marti E. 2008. Development of a smart' tracer for the assessment of microbiological activity and sediment-water interaction in natural waters: The 
resazurin-resorufin system. Water Resources Research 44 (4) DOI: 10.1029/2007wr006670

Hall RO, Bernhardt ES, Likens GE. 2002. Relating nutrient uptake with transient storage in forested mountain streams. Limnology and Oceanography 47: 255-265 DOI: 10.4319/lo.2002.47.1.0255

Harvey JW, Fuller CC. 1998. Effect of enhanced manganese oxidation in the hyporheic zone on basin-scale geochemical mass balance. Water Resources Research 34 (4): 623-636

Harvey JW, Wagner BJ. 2000. Quantifying hydrologic interactions between streams and their subsurface hyporheic zones (PJ Jones, Jeremy B. and Mulholland, ed.). Academic Press: San Diego. DOI: http://dx.doi.org/10.1016/B978-012389845-6/50002-8

Harvey JW, Böhlke JK, Voytek M a., Scott D, Tobias CR. 2013. Hyporheic zone denitrification: Controls on effective reaction depth and contribution to whole-stream mass balance. Water Resources Research 49 (10): 6298-6316 DOI: 10.1002/wrcr.20492

Harvey JW, Drummond JD, Martin RL, McPhillips LE, Packman AI, Jerolmack DJ, Stonedahl SH, Aubeneau AF, Sawyer AH, Larsen LG, et al. 2012. Hydrogeomorphology of the hyporheic zone: Stream solute and fine particle interactions with a dynamic streambed. Journal of Geophysical Research 117: G00N11 DOI: 10.1029/2012JG002043

Harvey JW, Wagner BJ, Bencala KE. 1996. Evaluating the reliability of the stream tracer approach to characterize stream-subsurface water exchange. Water Resources Research $\mathbf{3 2}$ (8): $2441-2451$

Hester ET, Gooseff MN. 2010. Moving beyond the banks: hyporheic restoration is fundamental to restoring ecological services and functions of streams. Environmental Science \& Technology 44 (5): 1521-1525 
Hester, ET and MN Gooseff. 2011. Hyporheic restoration in streams and rivers. Chapter in Stream Restoration in Dynamic Fluvial Systems: Scientific Approaches, Analyses, and Tools (Simon, A., S.J. Bennett, and J.M. Castro, Eds.).

Hester ET, Doyle MW, Poole GC. 2009. The influence of in-stream structures on summer water temperatures via induced hyporheic exchange. Limnology and Oceanography 54 (1): 355367 DOI: $10.4319 / 10.2009 .54 .1 .0355$

Hester, ET, Hammond B, and Scott DT. 2016. Effects of inset floodplains and hyporheic exchange induced by in-stream structures on nitrate removal in a headwater stream. Ecological Engineering 97:452-464.

Hester ET, Young KI, Widdowson MA. 2013. Mixing of surface and groundwater induced by riverbed dunes: Implications for hyporheic zone definitions and pollutant reactions. Water Resources Research 49 (9): 5221-5237

Hester ET and Doyle MW. 2008. In-stream geomorphic structures as drivers of hyporheic exchange. Water Resources Research 44 (3) DOI: 10.1029/2006wr005810

Hines SL, Hershey AE. 2011. Do channel restoration structures promote ammonium uptake and improve macroinvertebrate-based water quality classification in urban streams? Inland Waters 1 (2): 133-145 DOI: 10.5268/iw-1.2.395

Houde ED, Peladic SJ, Brandt SB, Leach SD. 1999. Fisheries: trends in catches, abundance and management. Ecosystems at the Land-Sea Margin: Drainage Basin to Coastal Sea: 341366

Howarth RW, Sharpley A, Walker D. 2002. Sources of Nutrient Pollution to Coastal Waters in the United States : Implications for Achieving Coastal Water Quality Goals. 25 (4): 656- 
676

Jin L, Siegel DI, Lautz LK, Otz MH. 2009. Transient storage and downstream solute transport in nested stream reaches affected by beaver dams. Hydrological processes 23 (17): 2438-2449

Johnson ZC, Warwick JJ, Schumer R. 2014. Factors affecting hyporheic and surface transient storage in a western US river. Journal of Hydrology 510: 325-339

Johnson ZC, Warwick JJ, Schumer R. 2015. A numerical investigation of the potential impact of stream restoration on in-stream N removal. Ecological Engineering 83: 96-107 DOI: 10.1016/j.ecoleng.2015.05.024

Kasahara T, Hill AR. 2006. Effects of riffle step restoration on hyporheic zone chemistry in Nrich lowland streams. Canadian Journal of Fisheries and Aquatic Sciences 63 (1): 120-133

Kemp WM, Boynton WR, Adolf JE, Boesch DF, Boicourt WC, Brush G, Cornwell JC, Fisher TR, Glibert PM, Hagy JD, et al. 2005. Eutrophication of Chesapeake Bay: historical trends and ecological interactions. Marine Ecology Progress Series 303 (21): 1-29

Lautz L, Fanelli R. 2008. Seasonal biogeochemical hotspots in the streambed around restoration structures. Biogeochemistry 91 (1): 85-104 DOI: 10.1007/s10533-008-9235-2

Lautz LK, Siegel DI. 2006. Modeling surface and ground water mixing in the hyporheic zone using MODFLOW and MT3D. Advances in Water Resources 29 (11): 1618-1633

Lautz LK, Siegel DI. 2007. The effect of transient storage on nitrate uptake lengths in streams: An inter-site comparison. Hydrological Processes 21: 3533-3548 DOI: 10.1002/hyp.6569

Lawrence JE, Skold ME, Hussain FA, Silverman DR, Resh VH, Sedlak DL, Luthy RG, McCray JE. 2013. Hyporheic Zone in Urban Streams: A Review and Opportunities for Enhancing Water Quality and Improving Aquatic Habitat by Active Management. Environmental 
Engineering Science 30 (8): 480-501 DOI: 10.1089/ees.2012.0235

Menichino GT, Hester ET. 2014. Hydraulic and thermal effects of in-stream structure-induced hyporheic exchange across a range of hydraulic conductivities. Water Resources Research 50 (6): 4643-4661

Miller JR, Kochel RC. 2013. Use and performance of in-stream structures for river restoration: a case study from North Carolina. Environmental Earth Sciences 68: 1563-1574 DOI: $10.1007 / \mathrm{s} 12665-012-1850-5$

Moore RD. 2004. Introduction to Salt Dilution Gauging for Streamflow Measurement : Part 1. Streamline Watershed Management Bulletin 7 (4): 20-23

Mueller M, Pander J, Geist J. 2014. The ecological value of stream restoration measures: An evaluation on ecosystem and target species scales. Ecological Engineering 62: 129-139 DOI: $10.1016 /$ j.ecoleng.2013.10.030

Mueller Price JS, Baker DW, Bledsoe BP. 2016. Effects of Passive and Structural Stream Restoration Approaches on Transient Storage and Nitrate Uptake. River Research and Applications 32: 1542-1554, DOI: 10.1002/rra.3013.

Nagaoka H, Ohgaki S. 1990. Mass transfer mechanism in a porous riverbed. Water Research 24 (4): 417-425

NRCS. 2007. Stream Restoration Design. In National Engineering Handbook714. Available at: http://www.nae.usace.army.mil/reg/nrrbs/Front-material/NEH654-Cover.pdf

Packman AI, Brooks NH. 2001. Hyporheic exchange of solutes and colloids with moving bed forms. Water Resources Research 37 (10): 2591-2605

Palmer MA, Filoso S, Fanelli RM. 2014. From ecosystems to ecosystem services: stream 
restoration as ecological engineering. Ecological Engineering 65: 62-70

Payn RA, Gooseff MN, McGlynn BL, Bencala KE, Wondzell SM. 2009. Channel water balance and exchange with subsurface flow along a mountain headwater stream in Montana, United States. Water Resources Research 45 (11): n/a-n/a DOI: 10.1029/2008WR007644

Phanikumar MS, Aslam I, Shen C, Long DT, Voice TC. 2007. Separating surface storage from hyporheic retention in natural streams using wavelet decomposition of acoustic Doppler current profiles. Water resources research $\mathbf{4 3}$ (5)

Roberts BJ, Mulholland PJ, Houser JN. 2007. Effects of upland disturbance and instream restoration on hydrodynamics and ammonium uptake in headwater streams. Journal of the North American Benthological Society 26 (1): 38-53

Roni P, Bennett T, Morley S, Pess GR, Hanson K, Slyke D Van, Olmstead P. 2006.

Rehabilitation of bedrock stream channels: the effects of boulder weir placement on aquatic habitat and biota. River Research and Applications 22 (9): 967

Rosgen, DL. 1994. A classification of natural rivers. Catena 22 (3): 169-199.

Runkel RL. 1998. One-dimensional transport with inflow and storage (otis): a solute transport model for streams and rivers. U.S. Geological Survey. Water-Resources Investigations Report 98-4018

Runkel RL. 2002. A new metric for determining the importance of transient storage. Journal of the North American Benthological Society 21 (4): 529-543 DOI: 10.2307/1468428

Scavia D, Bricker SB. 2006. Coastal eutrophication assessment in the United States. In Nitrogen Cycling in the Americas: Natural and Anthropogenic Influences and Controls: 187-208. Springer Netherlands. 
Schmid BH, Innocenti I, Sanfilippo U. 2010. Characterizing solute transport with transient storage across a range of flow rates: The evidence of repeated tracer experiments in Austrian and Italian streams. Advances in Water Resources 33 (11): 1340-1346

Scott DT, Keim RF, Edwards BL, Jones CN, Kroes DE. 2014. Floodplain biogeochemical processing of floodwaters in the Atchafalaya River Basin during the Mississippi River flood of 2011. Journal of Geophysical Research: Biogeosciences 119 (4): 537-546

Seitzinger SP, Styles R V, Boyer EW, Alexander RB, Billen G, Howarth RW, Mayer B, Breemen N Van. 2002. Nitrogen Retention in Rivers: Model Development and Application to Watersheds in the Northeastern U.S.A. Biogeochemistry 57/58: pp. 199-237

Stewart RJ, Wollheim WM, Gooseff MN, Briggs MA, Jacobs JM, Peterson BJ, Hopkinson CS. 2011. Separation of river network--scale nitrogen removal among the main channel and two transient storage compartments. Water Resources Research 47 (10)

Stonedahl SH, Harvey JW, Detty J, Aubeneau A, Packman AI. 2012. Physical controls and predictability of stream hyporheic flow evaluated with a multiscale model. Water Resources Research 48 (10)

USEPA. 2006. Wadeable Streams Assessment: A Collaborative Survey of the Nation's Streams. US Environmental Protection Agency, Office of Water, US Environmental Protection Agency, Washington DC: pp. 113

USEPA USEPA. 2010. Chesapeake Bay TMDL Available at: http://www.epa.gov/reg3wapd/tmdl/ChesapeakeBay/tmdlexec.html Valett HM, Morrice JA, Dahm CN, Campana ME. 1996. Parent lithology, surface-groundwater exchange, and nitrate retention in headwater streams. Limnology and Oceanography 41: 
333-345 DOI: 10.4319/1o.1996.41.2.0333

Veraart AJ, Audet J, Dimitrov MR, Hoffmann CC, Gillissen F, de Klein JJM. 2014.

Denitrification in restored and unrestored Danish streams. Ecological Engineering 66: 129140

Wagner BJ, Harvey JW. 1997. Experimental design for estimating parameters of rate-limited mass transfer : Analysis of stream tracer studies. Water Resources Research 33 (7): 17311741

Ward AS, Gooseff MN, Voltz TJ, Fitzgerald M, Singha K, Zarnetske JP. 2013a. How does rapidly changing discharge during storm events affect transient storage and channel water balance in a headwater mountain stream? Water Resources Research 49 (9): 5473-5486 DOI: $10.1002 /$ wrcr.20434

Ward AS, Payn RA, Gooseff MN, McGlynn BL, Bencala KE, Kelleher CA, Wondzell SM, Wagener T. 2013b. Variations in surface water-ground water interactions along a headwater mountain stream: Comparisons between transient storage and water balance analyses. Water Resources Research 49 (6): 3359-3374

Wenger SJ, Roy AH, Jackson CR, Bernhardt ES, Carter TL, Filoso S, Gibson CA, Hession WC, Kaushal SS, Martí E, et al. 2009. Twenty-six key research questions in urban stream ecology: an assessment of the state of the science. Journal of the North American Benthological Society 28 (4): 1080-1098

Wondzell SM. 2006. Effect of morphology and discharge on hyporheic exchange flows in two small streams in the Cascade Mountains of Oregon, USA. Hydrological Processes 20 (2): $267-287$ 
Workshop SS. 1990. Concepts and Methods for Assessing Solute Dynamics in Stream Ecosystems. Journal of the North American Benthological Society 9 (2): 95 DOI: $10.2307 / 1467445$

Ye S, Covino TP, Sivapalan M, Basu NB, Li H-Y, Wang S-W. 2012. Dissolved nutrient retention dynamics in river networks: A modeling investigation of transient flows and scale effects. Water Resources Research 48 (6)

Zaramella M, Packman AI, Marion A. 2003. Application of the transient storage model to analyze advective hyporheic exchange with deep and shallow sediment beds. Water Resources Research 39 (7)

Zarnetske JP, Gooseff MN, Brosten TR, Bradford JH, McNamara JP, Bowden WB. 2007. Transient storage as a function of geomorphology, discharge, and permafrost active layer conditions in Arctic tundra streams. Water Resources Research 43 (7)

Zarnetske JP, Haggerty R, Wondzell SM. 2015. Coupling multiscale observations to evaluate hyporheic nitrate removal at the reach scale. Freshwater Science 34 (1): 172-186

Zimmer MA, Lautz LK. 2015. Pre-and postrestoration assessment of stream water--groundwater interactions: effects on hydrological and chemical heterogeneity in the hyporheic zone. Freshwater Science 34 (1): 287-300 
Tables

Table 1. Experiment details and flows

\begin{tabular}{|c|c|c|c|c|c|c|c|}
\hline \multirow{2}{*}{$\begin{array}{l}\text { Exp. } \\
\text { ID }\end{array}$} & \multirow[t]{2}{*}{ Date } & \multirow{2}{*}{$\begin{array}{c}\text { Number } \\
\text { of } \\
\text { structures }\end{array}$} & & $\operatorname{eam~F}$ & & \multirow{2}{*}{$\begin{array}{l}\text { Injection } \\
\text { Start Time }\end{array}$} & \multirow{2}{*}{$\begin{array}{c}\text { Injection } \\
\text { Duration } \\
\text { (hrs) }\end{array}$} \\
\hline & & & Min & Avg & Max & & \\
\hline E1 & $5-11-2015$ & None & 14.3 & 14.6 & 14.9 & $10: 40 \mathrm{am}$ & 3.67 \\
\hline $\mathrm{E} 2$ & 5-19-2015 & 3 weirs & 8.6 & 8.7 & 8.8 & $3: 14 \mathrm{pm}$ & 3.00 \\
\hline E3 & $5-22-2015$ & 7 weirs & 6.9 & 7.05 & 7.2 & $11: 12 \mathrm{am}$ & 3.00 \\
\hline $\mathrm{E} 4$ & $5-30-2015$ & 10 weirs & 5.4 & 5.65 & 5.9 & 11:03 am & 3.95 \\
\hline E5 & $6-03-2015$ & 10 weirs & 6.7 & 6.90 & 7.1 & 11:29 am & 4.7 \\
\hline E6 & 6-09-2015 & 10 weirs & 3.9 & 4.40 & 4.9 & $11: 27 \mathrm{am}$ & 4.75 \\
\hline
\end{tabular}


Table 2. Summary of conservative tracer parameters.

\begin{tabular}{|c|c|c|c|c|c|c|c|c|c|c|}
\hline Exp & Reach & $\begin{array}{c}\mathrm{Q} \\
(\mathrm{L} / \mathrm{s})\end{array}$ & $\begin{array}{c}\# \\
\text { of } \\
\text { weirs }\end{array}$ & $\begin{array}{c}t_{n} \\
\text { (mins) }\end{array}$ & $\begin{array}{c}\% \\
F_{m e d}^{200}\end{array}$ & $\begin{array}{c}u \\
(\mathrm{~m} / \mathrm{s})\end{array}$ & $\begin{array}{c}D \\
\left(\mathrm{~m}^{2} / \mathrm{s}\right)\end{array}$ & $\begin{array}{c}A \\
\left(\mathrm{~m}^{2}\right)\end{array}$ & $\begin{array}{c}A_{s} \\
\left(\mathrm{~m}^{2}\right)\end{array}$ & $\begin{array}{c}\alpha \\
\left(\mathrm{s}^{-1}\right) \\
\times 10^{-4}\end{array}$ \\
\hline \multirow{2}{*}{ E1 } & Cont. & \multirow{2}{*}{14.6} & -- & 10.2 & 0.53 & 0.131 & 0.417 & 0.105 & 0.030 & 2.0 \\
\hline & Treat. & & 0 & 8.2 & 1.80 & 0.162 & 0.329 & 0.082 & 0.009 & 1.7 \\
\hline \multirow{2}{*}{ E2 } & Cont. & \multirow{2}{*}{8.70} & -- & 15.6 & 0.60 & 0.085 & 0.236 & 0.099 & 0.041 & 2.0 \\
\hline & Treat. & & 3 & 16.5 & 4.25 & 0.081 & 0.216 & 0.102 & 0.022 & 1.2 \\
\hline \multirow{2}{*}{ E3 } & Cont. & \multirow{2}{*}{7.05} & -- & 17.3 & 0.64 & 0.077 & 0.231 & 0.087 & 0.033 & 1.8 \\
\hline & Treat. & & 7 & 24.5 & 2.90 & 0.054 & 0.160 & 0.124 & 0.021 & 0.63 \\
\hline \multirow{2}{*}{ E4 } & Cont. & \multirow{2}{*}{5.65} & -- & 20.6 & 0.50 & 0.065 & 0.246 & 0.082 & 0.051 & 1.6 \\
\hline & Treat. & & 10 & 36.4 & 4.60 & 0.037 & 0.106 & 0.144 & 0.028 & 0.63 \\
\hline \multirow{2}{*}{ E5 } & Cont. & \multirow{2}{*}{6.90} & - & 17.9 & 0.58 & 0.075 & 0.208 & 0.087 & 0.040 & 1.8 \\
\hline & Treat. & & 10 & 27.8 & 3.40 & 0.048 & 0.129 & 0.135 & 0.031 & 0.51 \\
\hline \multirow{2}{*}{ E6 } & Cont. & \multirow{2}{*}{4.40} & -- & 22.7 & 0.40 & 0.059 & 0.260 & 0.076 & 0.049 & 1.1 \\
\hline & Treat. & & 10 & 35.1 & 4.56 & 0.038 & 0.109 & 0.114 & 0.022 & 0.65 \\
\hline
\end{tabular}


Table 3. Damköhler numbers

\begin{tabular}{|c|c|c|c|c|}
\hline \multirow{2}{*}{ Exp } & \multicolumn{2}{|c|}{ Dal (--) } & \multicolumn{2}{c|}{$\begin{array}{c}\text { Mean Squared } \\
\text { Error }\left(\mu \mathrm{S}^{2} / \mathrm{cm}^{2}\right)\end{array}$} \\
\cline { 2 - 5 } & Control & Treatment & Control & Treatment \\
\hline E1 & 0.53 & 0.74 & 0.195 & 0.046 \\
\hline E2 & 0.60 & 0.65 & 0.361 & 0.067 \\
\hline E3 & 0.64 & 0.60 & 0.730 & 0.742 \\
\hline E4 & 0.50 & 0.84 & 4.683 & 3.954 \\
\hline E5 & 0.58 & 0.43 & 1.500 & 0.451 \\
\hline E6 & 0.40 & 0.84 & 2.155 & 5.989 \\
\hline
\end{tabular}




\section{Figures}

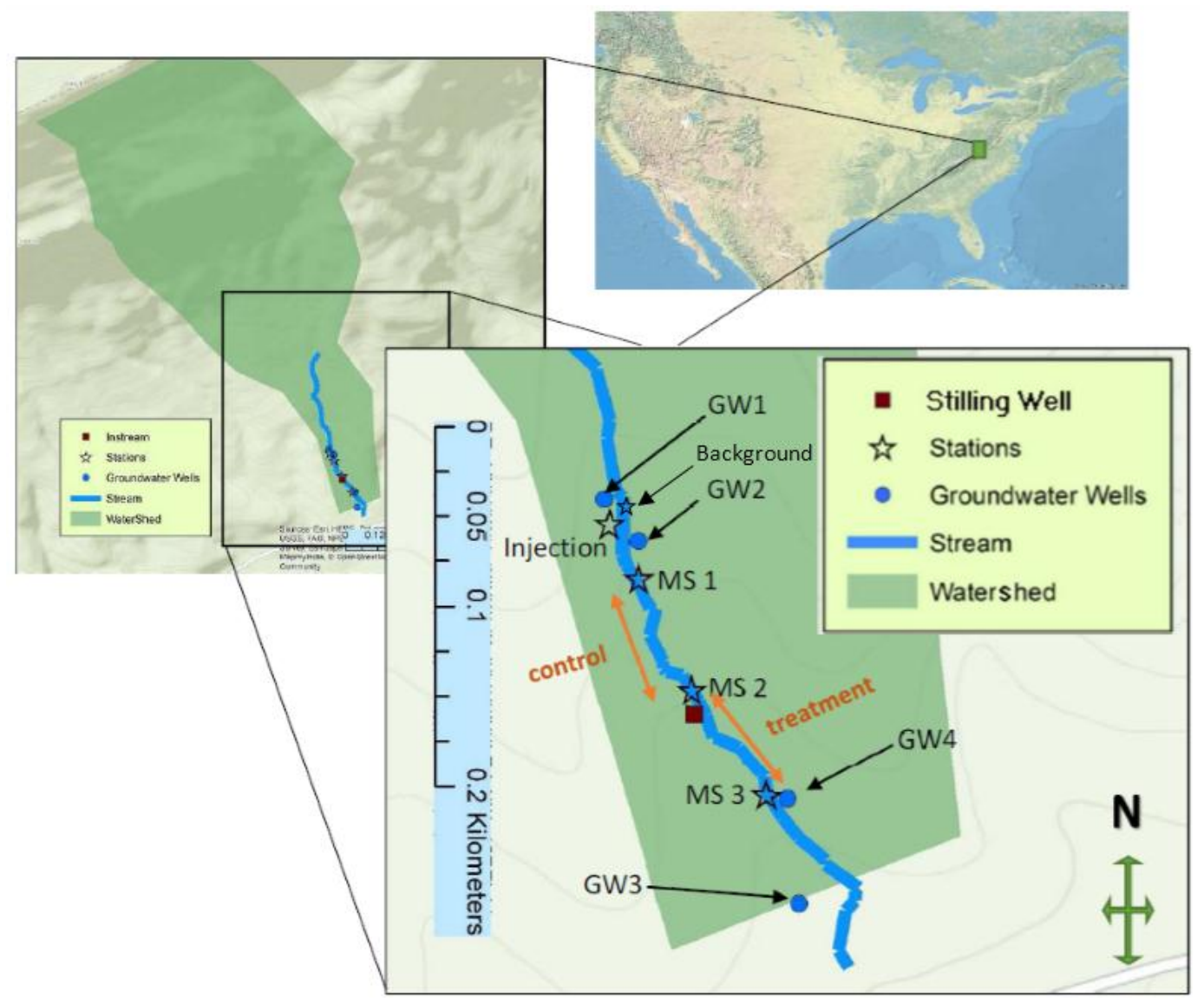

Figure 1. Map showing the stream location, watershed, monitoring and injection stations (background, injection, MS1, MS2 and MS3), groundwater wells (GW1 through GW4) and instream stilling well. 


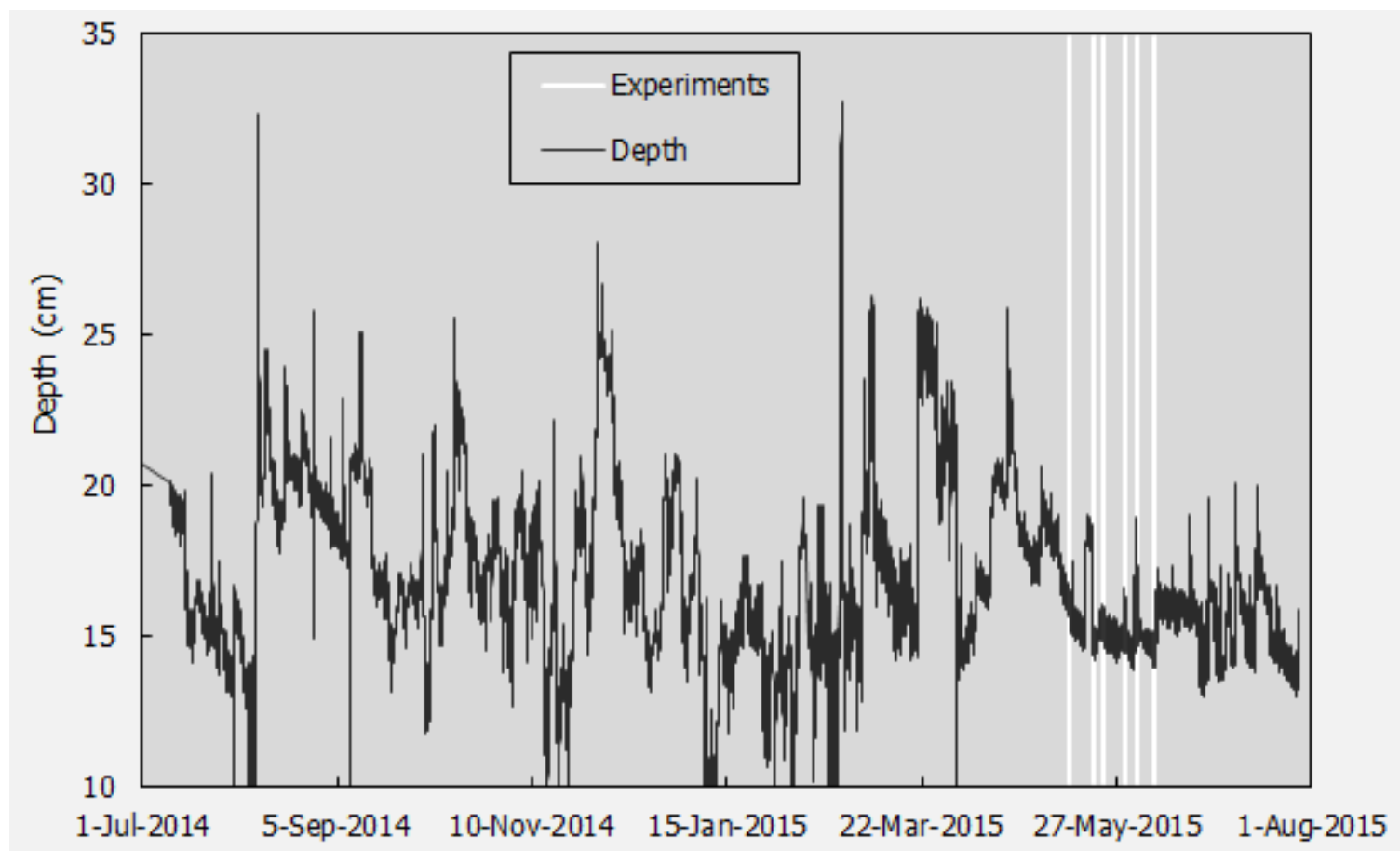

Figure 2. Stream water depth versus date at stilling well (see Figure 1 for location). Vertical lines correspond to the dates of the experiments.

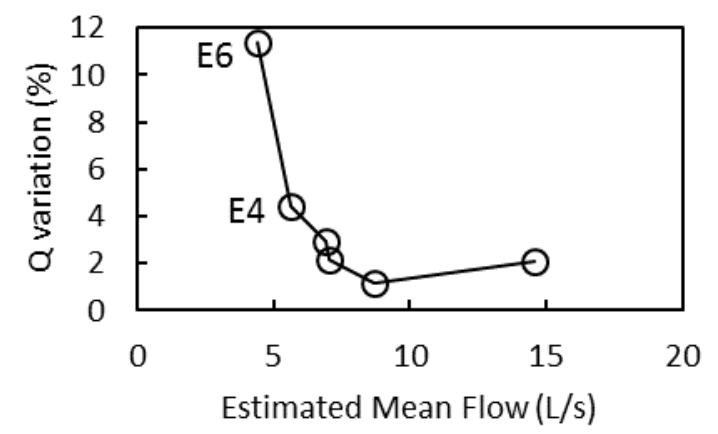

Figure 3. Sub-daily channel flow rate $(Q)$ variation (in percent) estimated from mean $Q$ and specific conductance plateau slope during each experiment versus mean $Q$. 

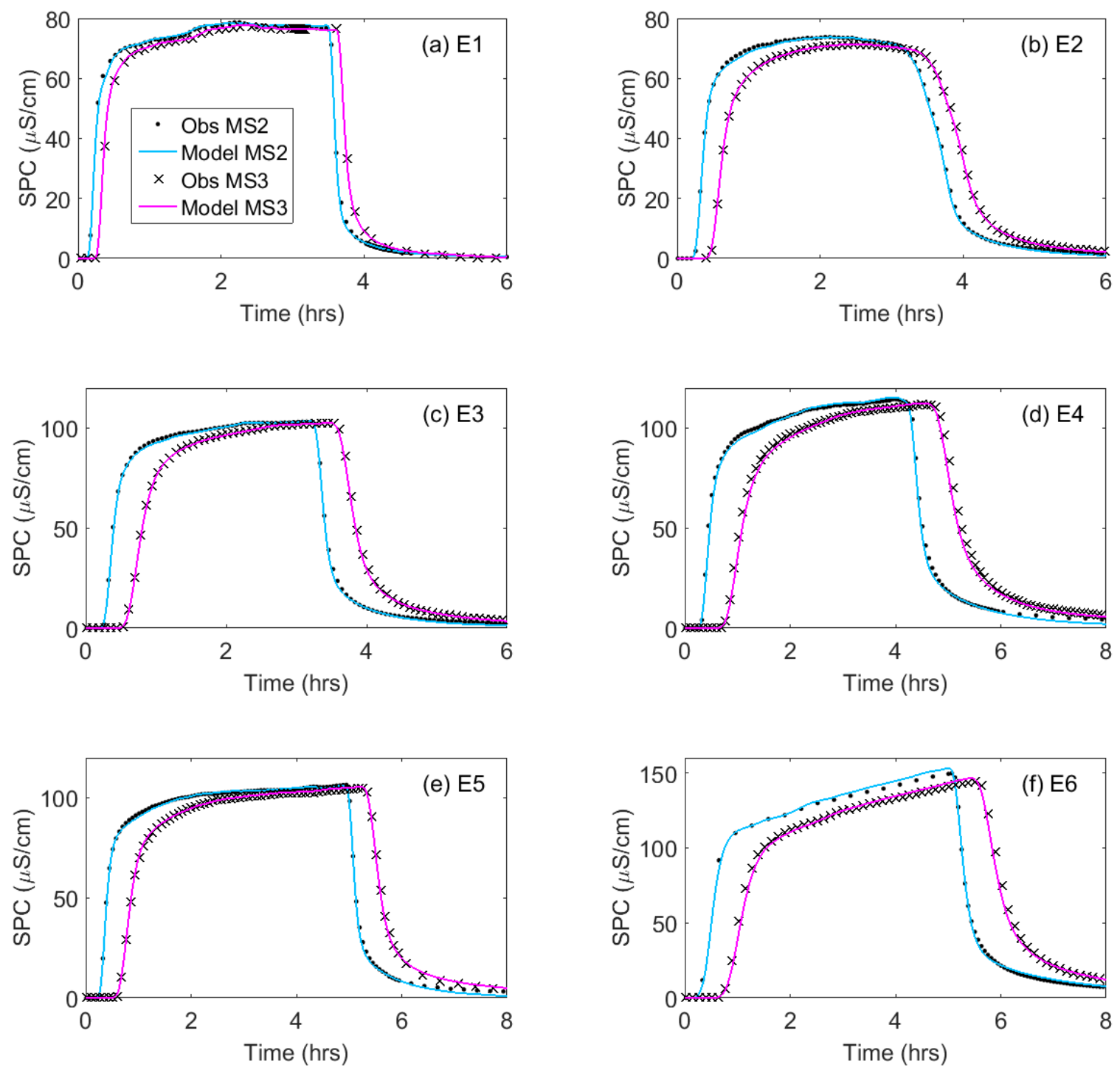

Figure 4. Modeled and observed specific conductance breakthrough curves at monitoring station 2 and 3 (MS2 and MS3) for E1 through E6 shown in panel (a) through (f). SPC=specific conductance. 

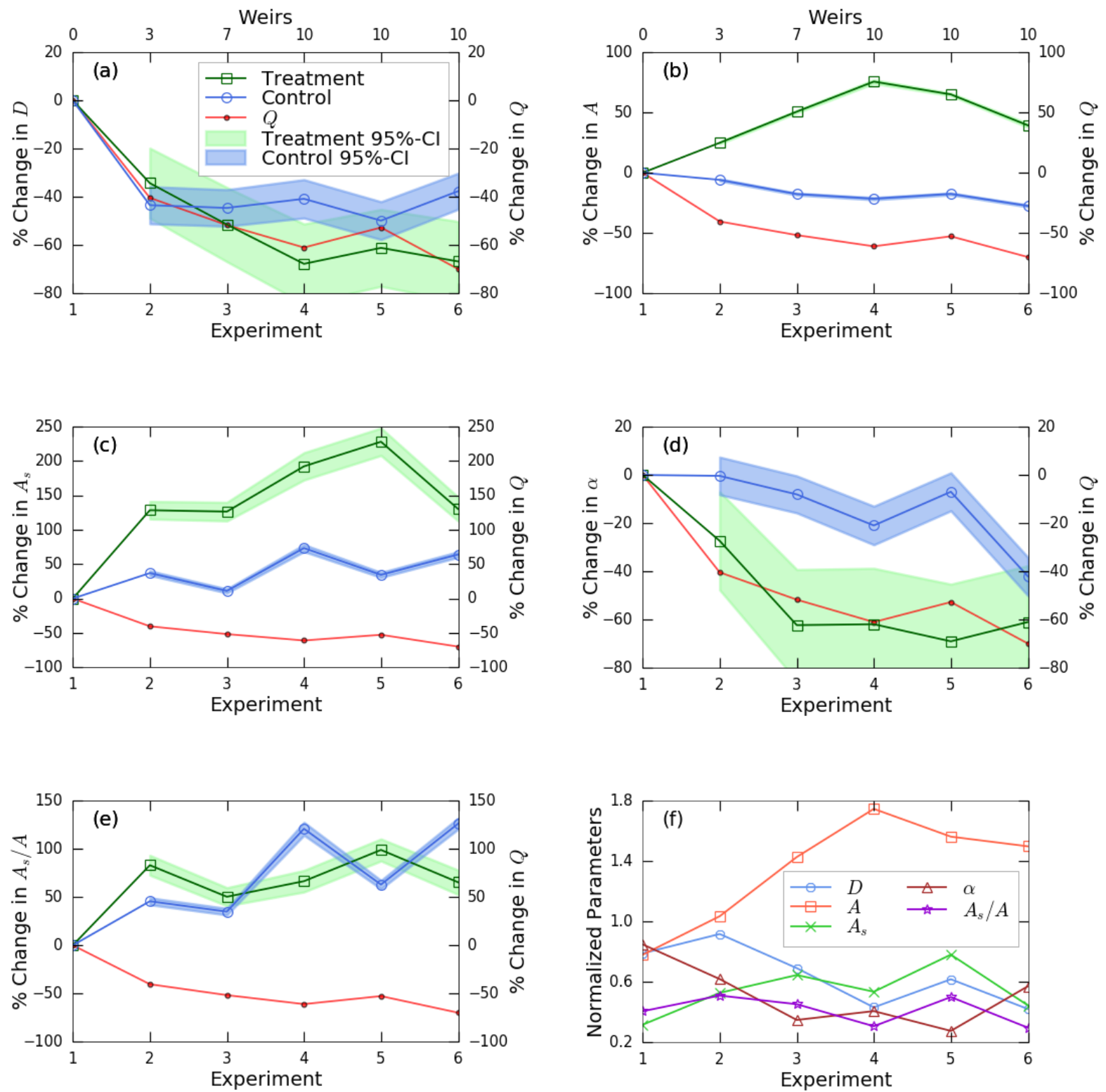

Figure 5. (a through e) Change of transient storage parameters relative to their values estimated in the first experiment versus experiment number along with propagated $95 \%$ confidence interval (note that, due to normalization with respect to E1, uncertainty for the E1 cannot be calculated); and (f) Parameters of the treatment reach normalized by the 
corresponding parameter of the control reach versus experiment number. $A=$ channel cross sectional area, $A_{s}=$ transient storage zone cross sectional area, $\alpha=$ transient storage zone exchange rate, $D=$ channel dispersion coefficeint.
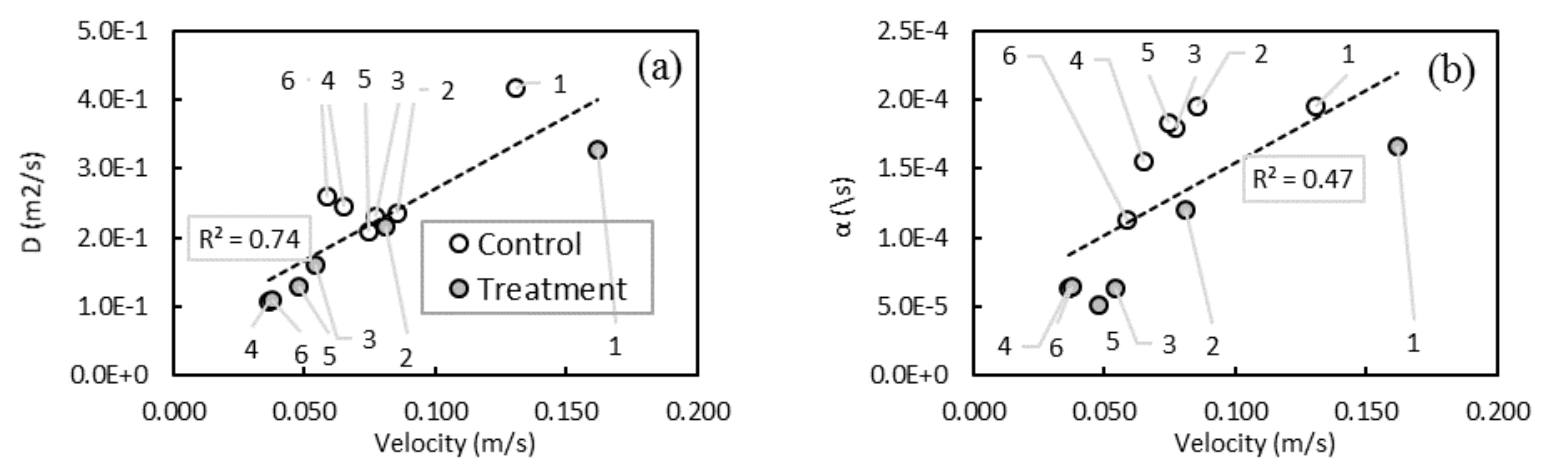

Figure 6. (a) Channel dispersion coefficient $\left(D, \mathrm{R}^{2}=0.74\right)$ and (b) and transient storage exchange rate $\left(\alpha, \mathrm{R}^{2}=0.47\right)$ versus $u$ for the six experiments. 

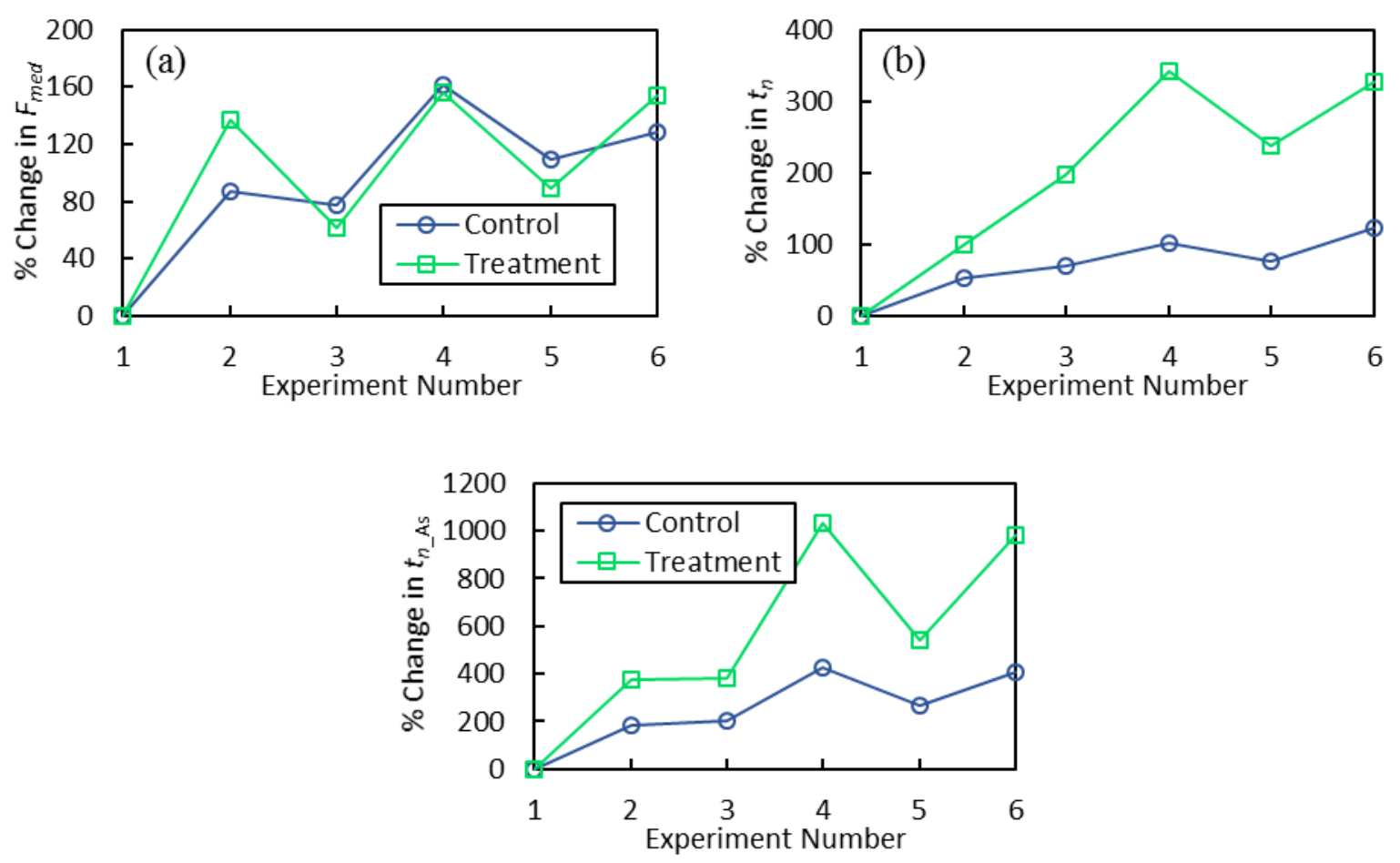

Figure 7. Change in (a) $F_{\text {med }}^{200}$; (b) channel median residence time $\left(t_{n}\right)$; and (c) part of $t_{n}$ that is due to transient storage $\left(t_{n_{-} A s}\right)$, as a percentage of their initial values from experiment E1 versus experiment number. $\mathrm{TS}=$ transient storage. 

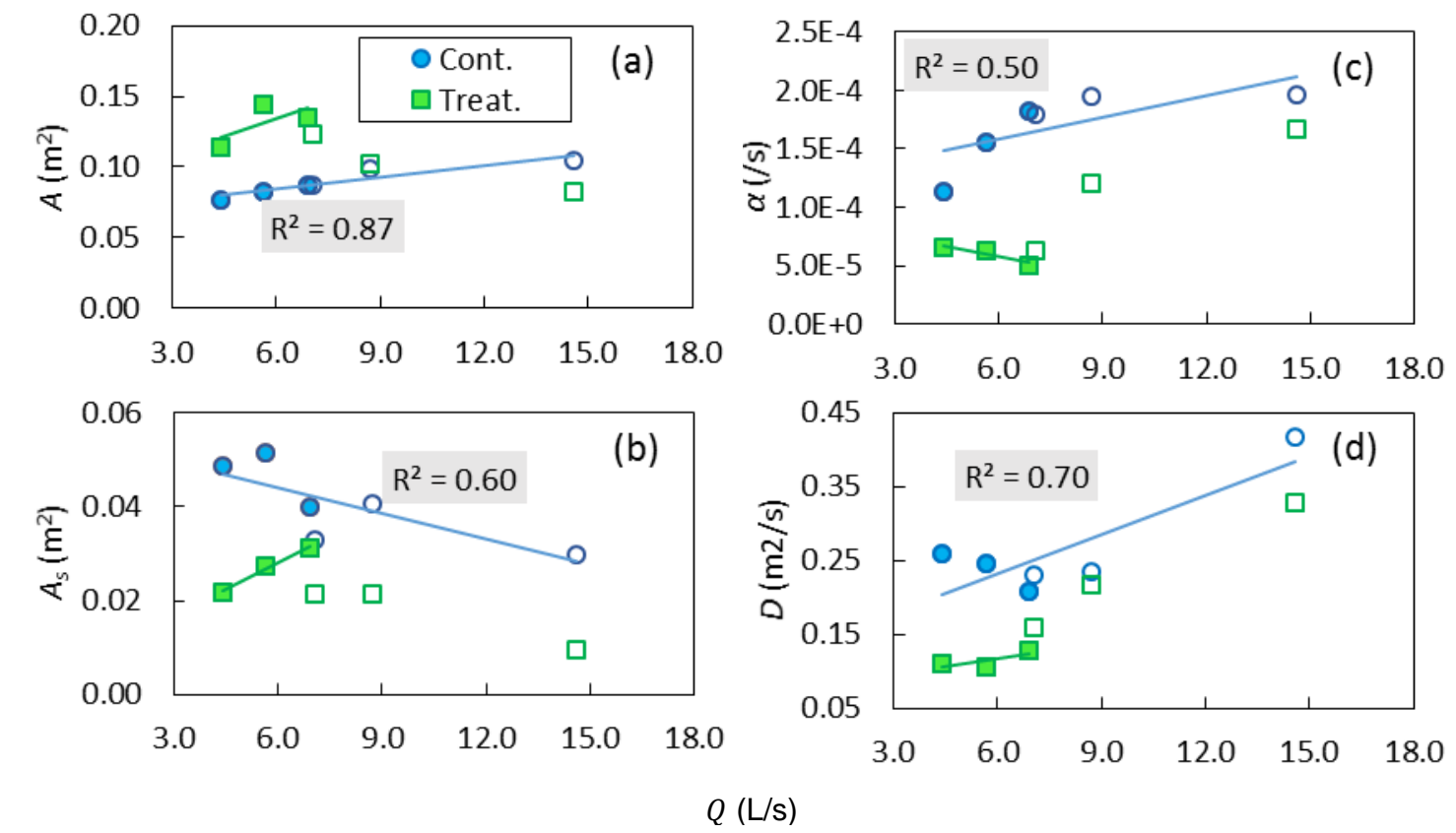

Figure 8. Channel cross sectional area $(A)$, transient storage zone cross sectional area $\left(A_{s}\right)$, transient storage zone exchange rate $(\alpha)$ and channel dispersion coefficient $(D)$ plotted against channel flow rate $(Q)$ for the control reach and treatment reach. Filled markers indicate the last three experiments (E4 - E6) when the number of weirs remained constant. $\mathrm{R}^{2}$ values are given only for the control reach. Trend lines for the control reach are for all six experiments while trend lines for the treatment are only for E4-E6. 